\title{
Generating New Ideas for Global Governance: The World Economic Forum's Global Redesign Initiative*
}

\author{
Matthias Catón
}

How can we solve global challenges such as climate change, monetary imbalances, the sovereign debt crisis, threats from terrorism and failed states? Experts and decision-makers disagree on how to best tackle these issues, but few people would doubt that the number of global challenges-problems that no country can solve on its own-has risen and that the world today is a more complex place than it used to be. Our inability to address many of these issues in a comprehensive way directly affects the lives of millions in all parts of the world.

It seems that many of the international structures, frameworks and institutions are inadequate or outdated. They do not match the level of complexity and interdependence and most are stuck in the narrow silos of professional expertise.

\section{Structured collaboration - a new model for solving global challenges}

Few people would doubt that the complexity of our world and the magnitude of the problems need creative new ideas that look beyond the narrow confines of expert circles. Yet, there is not much thought given to how these ideas can be generated. The traditional model of advice rests on the expert, who has achieved his or her status through traditional proofs (publications, past experience).

With the development of new communication technology a new form of knowledge generation became feasible, which is sometimes called the Wiki model and relies on the "wisdom of the crowds". It rests on the assumption that everybody is welcome to contribute and that the more people do so, the better the outcome will be.

While the traditional expert model is exclusive, the Wiki model is inclusive. Both approaches have their place. I argue, however, that most of the complex challenges we face globally require a new approach that sits between these extremes. We need creative collaboration of fairly large numbers of diverse experts in guided, moderated processes. Innovative new ideas only emerge if there is cross-collaboration, and that only happens if it is enforced. A guiding framework gives direction without predetermining the outcome. The framework is needed to overcome certain limitations of the other two approaches and to ensure three key elements for successful collaborative innovation:

1. diverse views

2. a common purpose or direction (the "what")

3. a process (the "how")

4. a holistic view across expertise borders

\section{Using the World Economic Forum's convening power}

In 2009, the World Economic Forum under the leadership of its Founder and Executive Chairman Klaus Schwab launched the Global Redesign Initiative (GRI), an ambitious attempt to bring together a large number of the best global experts and practitioners to generate new solutions for reforming global cooperation.

The Forum, in existence for over forty years, has a longstanding reputation for being the foremost organizer of meetings for leaders from business and governments. The best known of these is the Annual Meeting in Davos. It had always been more than meetings, though, and over the past couple of years it has increasingly evolved into a platform and catalyst for global ideas not just limited to physical encounters.

In 2008 the Forum had set up its Network of Global Agenda Councils (GAC). It brings together the world's foremost experts around the most pressing issues on the global agenda. Currently, there are more than seventy Councils covering topics ranging from Alternative Energies to the Welfare of Children. Each of them has fifteen to twenty members, representing a mix of world class academics and top-level practitioners from business, public sector and civil society.

The Councils meet each year during the 'Summit on the Global Agenda' in the United Arab Emirates. In between, they interact using a dedicated online platform that provides video conferencing facilities and other collaborative functions. What makes the GACs unique is the ability to develop ideas by reaching beyond the closed circles of specialists. Councils can use the network to easily connect to experts on a wide range of related issues.

The GACs were to become the intellectual backbone of the initiative, together with the Forum's other partners. The organization's base is its membership, around 1,000 globally operating, large companies. They are organized in different industry-specific groups, many of which actively work on contentrelated projects of their own. In addition, there are other stakeholders the Forum interacts with, most notably the Young Global Leaders-a community for leaders from different walks of life under the age of 40-and the social

\footnotetext{
* For more information go to www.caton.de/gri. where you will find links to the full proposals and chapters of the reports discussed in the article, videos from the IdeasLabs in Davos and from other GRI events. The views and opinions expressed in this article are those of the author and do not necessarily coincide with those of the World Economic Forum or the Frankfurt School of Finance \& Management. The author thanks Rick Samans, Michele Petochi and Mike Mirchandani for valuable feedback on draft versions of this article.
} 
entrepreneurs, organized by the Schwab Foundation for Social Entrepreneurship, which is closely linked to the Forum.

From the outset we were convinced that the World Economic Forum, a neutral non-governmental platform, would be ideal to structure and moderate an endeavor as the GRI. We knew that many of the proposals would touch the domain of government activity, though, which is why we wanted to have governmental endorsement throughout the process. We invited the governments of Qatar, Singapore and Switzerland to become patron governments of the initiative (Tanzania joined later). Why these countries? We looked for countries from different parts of the world that were small enough not to be great powers, but had a respectable standing in international affairs.

The GRI was run by a small core team of about six people, working under the leadership of Richard Samans, one of the Forum's Managing Directors. He was later joined by Mark Malloch Brown, a former UN Deputy Secretary-General, who became Senior Adviser to the initiative and later Vice-Chairman of the World Economic Forum. The core team was small, but the initiative involved almost every one of the $400+$ staff in one way or another. The core team's main tasks were therefore the strategic development of the GRI and a significant amount of coordination internally and externally. The initiative was a collaborative effort both within and outside the organization.

\section{Project Phases}

\section{Development of Proposals}

The project was planned in four phases that lasted between two months and roughly one year (see project timeline). During the first phase we set up the different working groups, gathered ideas and developed rough drafts of proposals. One of the first tasks was to contact the Forum's different groups -members and constituents in the organization's jargon-to let them know about the endeavor and get them on board. The main contributors would be Global Agenda Councils. The GACs were just completing their first one-year term and both the Forum and most of the network's members considered it a success. The Councils had lacked, however, a specific task or objective they could take on. The GRI would provide such an opportunity for the second term.

We invited all groups to join the effort and start developing new ideas. We left the task purposefully as open as possible. For example, we did not give any indications on which topics the groups should focus on. We only made three requests. Proposals should (1) address a problem of global governance or global cooperation, be (2) concrete suggestions on what should be done and how rather than mere analyses of a problem and (3) count on a reasonable consensus within the group, as we wanted to stress the collaborative aspect of idea creation, which would in and by itself give the proposals legitimacy.
The work would be done both offline and online. We used the Forum's big regional meetings to set up specific workshops and sessions around key topics. For example, at the Annual Meeting of the New Champions in Dalian in September 2009 we discussed ideas for a renewed international monetary policy, drawing from the lessons of the financial crisis. In addition, we used the Forum's existing collaborative functions on the web that provide document sharing, video conferencing, discussion boards and other facilities. The Summit on the Global Agenda in Dubai in November 2010, the GACs' annual meeting, was the place where draft proposals were finalized.

With our patron governments Qatar, Singapore and Switzerland we organized three so called Country Hearings that took the discussions directly to those countries and offered local and regional experts an opportunity to contribute to the process. The topics where chosen to reflect priorities of the patron countries. At the Swiss Country Hearing in Geneva around 100 academics and senior representatives of international organizations discussed questions of international institutional frameworks. The Country Hearing in Doha addressed the issue of energy security and the meeting in Singapore was about Asia's role in global governance.

\section{Feedback and Review}

The biggest opportunity for feedback was the Annual Meeting 2010 in Davos at the end of January. More than 2,000 of the world's leaders assembled in one spot was the ideal moment to test some of the ideas our working groups had come up with.

It is true that almost everybody who counts in global affairs is in this Swiss mountain village, but it is also true that everybody is extremely busy. Therefore, we took a special session format that the Forum's programming team had developed and adapted it to our needs. The IdeasLab relies on short presentations of five minutes using a Pecha Kucha ${ }^{1}$ format, which makes for very snappy, dynamic presentations. After a number of presentations the audience breaks into working groups, where participants can discuss with the presenter and give feedback.

This forced our presenters into a pretty rigid frame which not all of the renowned experts immediately appreciated, but it allowed us to fit five presentations and the group discussion into a 75 minute session. The GRI had four thematically grouped IdeasLabs, so we managed to get twenty proposals discussed in Davos.

We also realized that the vast array of topics that were covered in the proposals needed some additional structure to tie them together. We defined nine themes (values; economic growth; international monetary and financial system; employment, poverty and social welfare; risks; health; security; sus-

1 Pecha Kucha is a presentation form developed in Japan. In its original format it uses twenty slides, with each slide being shown for 20 seconds, making a presentation 6 minutes and 40 seconds long. 
tainability; and effective institutions) and asked renowned thought leaders to act as rapporteurs, writing cluster chapters that would put the proposals into a bigger context.

\section{Finalization of Proposals}

Most of the time in this phase went into editing, primarily to give all proposals a common structure and remove jargon as much as possible. All proposals start with a section providing the context, followed by the proposal itself and a more indepth explanation, including a rationale. Where appropriate, a section on the next steps and an appendix follow. All proposals end with a list of the people behind it, making it easier for readers to assess the weight of the idea.

Our 16 rapporteurs read all proposals and wrote the overarching thematic chapters. The World Economic Forum provided an introductory chapter, written by the two initiative leads Richard Samans and Mark Malloch Brown, together with the Forum's Executive Chairman Klaus Schwab.

The report has three layers of abstraction: the 58 proposals, the 9 thematic chapters and the overarching introduction, which draws general recommendations for an enhanced model of global cooperation. The report, entitled Everybody's Business: Strengthening International Cooperation in a More Interdependent World (World Economic Forum, 2010) has 600 pages and is available in an electronic version only.

The outcome was presented at a big international meeting, the Global Redesign Summit, which the World Economic Forum co-hosted and co-organized with the Government of Qatar in Doha in May 2010. We primarily invited two groups of people: the experts who had been the primary driving forces behind the proposals and decision-makers who would have the power to put them into practice. Senior government officials from around the world, representatives of international organizations and business leaders were thrown into a threeday marketplace of ideas. The 450 participants from 60 countries discussed intensely. Almost all sessions where interactive, designed to facilitate the presentation of ideas and the discussion of possible next steps.

\section{Outreach and dissemination}

This final phase was the longest in terms of time, but it was also the least intensive in terms of the level of activity. Following the presentation of the ideas in Doha we started to get a wider audience for the proposals, to make decision-makers around the world aware of them. To track our progress we created an internal database that contained all 58 proposals and the overarching themes. There, we logged all interactions and follow-ups.

Most of it was done one-on-one. The members of the GRI core team and the Forum's board members used many opportunities to meet with senior officials to present some of the ideas. We primarily used the different large Forum events to reach out to people attending. We would pick a number of proposals from the large pool and tailor it to the interests of the interlocutor. For example, at the Annual Meeting of the New Champions in Tianjin, China, in September 2010, GRI staff met with senior officials from the Asian Development Bank, the OECD, the World Intellectual Property Organization, the National Bank of Poland, the US Department of Commerce, the WTO and with several other national government officials to present and discuss specific proposals. In addition to decision-makers we also approached media leaders and placed a number of op-eds (Catón, 2010; Samans, Schwab \& Malloch-Brown, 2011).

In addition to individual outreach we organized a series of sessions at Forum events and two standalone symposia. The purpose was the same: make relevant people aware of the ideas so that they would be taken up, developed further and ultimately be implemented. Given the enormous bandwidth of the proposals we had to focus. e used initial feedback to gauge which ideas met the most interest, we matched issues to geographical regions and finally we tried to focus on those fields with no in-house teams able to drive them forward. For example, the World Economic Forum has a large and very active environmental team, so we could be certain that everything in that area would be taken care of as part of our colleague's ongoing activities. We decided to publish an edited book version of the initial report that would also be available in hard copy and which only includes a selection of the proposals (Samans, Schwab \& Malloch-Brown, 2010).

The first of the two symposia took place in Tokyo in October 2010. It dealt with the concept of human security, an issue that is at the core of Japanese foreign policy. We chose the Japanese Ministry of Foreign Affairs and Keio University as partners. The second symposium was in Berlin in March 2011 on global governance and risks. Partners were the German Ministry of Foreign Affairs (Auswärtiges Amt) and SWP, the German Institute for International and Security Affairs, Germany's most important foreign policy think tank. Sessions addressed the topics of economic governance, security governance and sustainability.

Both events lasted for one day and had around 100 participants each. With them, we reached a primarily national audience of academics, politicians, government officials and NGO representatives, many of which do not normally attend World Economic Forum events.

We also organized smaller, invitation-only sessions at the Annual Meeting in Davos in January 2011 (on human security, as a follow-up to the Tokyo symposium), at the World Economic Forum on Africa in Cape Town in May (on new paradigms for development cooperation) and at the World Economic Forum on East Asia in Jakarta in June (on trade). 


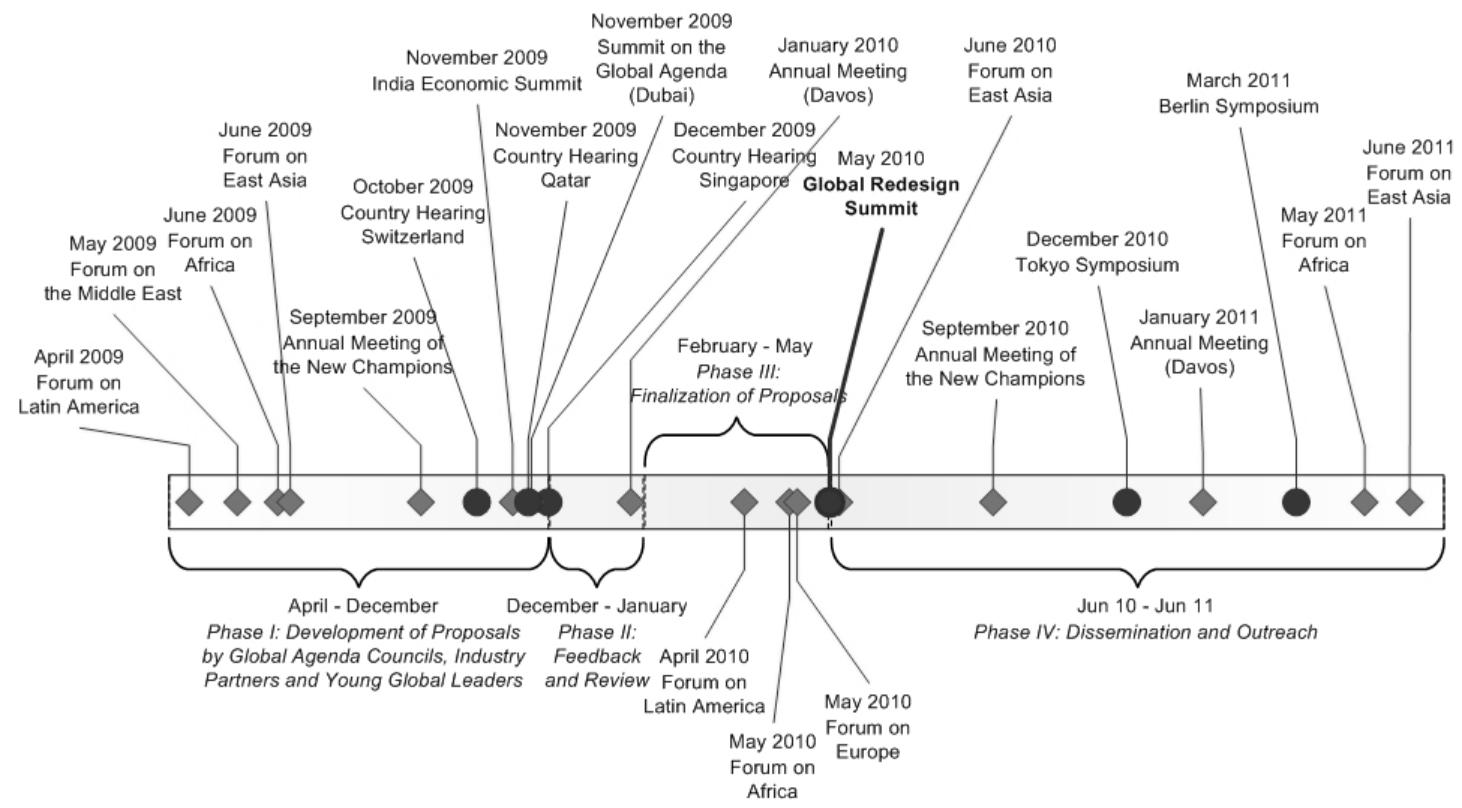

Figure : Project timeline

\section{Outcome}

The GRI as a project lasted for about $2 \frac{1 / 4}{4}$ years and included twenty-one events-six exclusively GRI-related events and fifteen larger Forum gatherings with GRI sessions. The outcome was a rich, very broad pool of ideas on how to enhance global cooperation to tackle some of the world's foremost challenges.

Not all ideas are completely new, of course, but many of them are highly innovative in the way they look at problems from a fresh angle and provide creative solutions by combining elements in an intelligent way. What makes those ideas appealing is that they go beyond simply demanding more resources. Instead, they combine different problems in nifty ways. For example, the proposal to create Sustainable Energy Free Trade Areas combines the need for private sector incentives to invest in sustainable energy products with more trade liberalization. The New Humanitarian Business Model wants to bring business, governments and community organizations together to provide assistance to countries in emergency situations. The Global Civilian Nuclear Fuel Cycle Partnership is a global public-private partnership to manage the civilian nuclear fuel cycle as a means of reducing the risk of nuclear weapons proliferation.

The collaborative element-roughly 1,500 people were involved in one way or another, most of them well-known experts and practitioners-give the proposals weight and legitimacy. The two main GRI publications (Samans et al., 2010; World Economic Forum, 2010) provide compendia for global governance reform that bundle ideas in a comprehensive, but easily accessible way.

The GRI as a project of the World Economic Forum ended as planned in mid-2011. Alas, that does not mean that the problems it addressed have been solved, but we hope that the ideas will live on.
The Initiative was an experiment. It has proven that large structured collaboration processes can be done and could be applied to other issues as well. The approach, however, needs to be developed further, using the experience of the GRI as a basis.

\section{Literature}

Samans, R., Schwab, K., \& Malloch-Brown, M. (2010). Global Redesign: Strengthening International Cooperation in a More Interdependent World. Cologny/Geneva: World Economic Forum.

Samans, R., Schwab, K., \& Malloch-Brown, M. (2011). Running the World, After the Crash. Foreign Policy, (January/February).

World Economic Forum. (2010). Everybody's Business: Strengthening International Cooperation in a More Interdependent World. Report of the Global Redesign Initiative. Cologny: World Economic Forum.

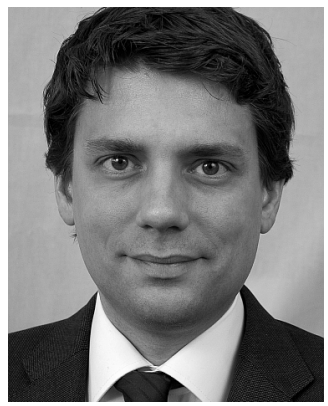

Matthias Catón is a Program Director at the Frankfurt School of Finance \& Management. From 2008 to 2011 he worked at the World Economic Forum in Geneva, where he was part of the Global Redesign Initiative's core team, first as Head of Project Management and later as Associate Director. He holds a Doctorate in Political Science from the University of Heidelberg and an Executive Master in Global Leadership from the World Economic Forum in collaboration with INSEAD, The Wharton School, London Business School and Columbia University.Email:matthias@caton.de 